\title{
Suma cero, la tradición contenciosa y las teorías contemporáneas de resolución de conflictos
}

Jorje H. Zalles

\begin{abstract}
Es muy clara para mí la superior validez normativa, en casi toda situación, del esquema "suma positiva". La influencia de pensamiento, actitudes y comportamientos "suma positiva" sobre la evolución y la eventual resolución de conflictos sociales demuestra con claridad el principal fundamento para este juicio de valor en el terreno de la ética social
\end{abstract}

\section{INTRODUCCIÓN}

Este artículo examina algunas de las implicaciones, en especial para el manejo y la resolución de conflictos, de dos distintos esquemas relacionados a los posibles desenlaces de las relaciones entre personas y/o grupos humanos, el denominado "esquema suma cero" y el que propongo denominar "esquema suma positiva". En las siguientes secciones del artículo, examino la naturaleza, las implicaciones más importantes, los orígenes y la validez de cada esquema, y la relación entre ellos y la transición del uno al otro.

En general, propongo que el denominado "esquema suma cero" es negativo en el contexto del conflicto y su resolución, porque (a) tiende a alentar a que el conflicto surja, escale, y evolucione a través de dinámicas de escalamiento más intensas, destructivas y permanentes, y por otro lado (b) tiende a desalentar y dificultar procesos de desescalamiento y de resolución negociada de conflictos.

$\mathrm{El}$ análisis se presenta, en general, en términos de relaciones bilaterales entre personas y grupos humanos. Sin embargo, la lógica del análisis es aplicable en situaciones multilaterales, aunque en dichas situaciones intervienen elementos adicionales, tanto reales como conceptuales, que no abordo en este artículo.

\section{EL CONTENIDO DE LOS DOS ESQUEMAS}

\section{El término "esquema"}

Utilizo el término "esquema" para describir un conjunto de elementos sicológicos, incluidos (a) pensamientos cognitivos, (b) actitudes y (c) comportamientos. Esta

aclaración es necesaria porque en la literatura especializada se encuentran frecuentes referencias solamente al aspecto cognitivo de los esquemas que analizo en este artículo ${ }^{1}, \mathrm{y}$, como pretendo demostrar con este análisis, es importante tomar en cuenta también los demás aspectos que en conjunto conforman los denominados "esquemas".

\section{Elementos cognitivos (I)}

Pensamiento "suma cero"

Una de las formas de concebir, cognitivamnete, el posible desenlace de una situación o relación entre personas o grupos humanos - un matrimonio, padres e hijos, profesores y alumnos, clientes y proveedores, partes en conflicto - es el denominado "pensamiento suma cero", que concibe sólo dos posibles desenlaces de esa relación bilateral entre A y B:

Gana A y Pierde B, que se expresa como (G,P) 0

Pierde A y Gana B, que se expresa como $(P, G)$

$\mathrm{Si}$ se trata de un negocio, el "pensamiento suma cero" tiene como premisa que la ganancia del comprador es la pérdida del vendedor, o viceversa; si se trata de un matrimonio, se plantea que la felicidad del marido sólo puede ser a costa de la infelicidad de la mujer, o viceversa. En toda situación, se piensa que hay un "ganador" y un "perdedor".

El significado preciso del término "suma cero" se explica así: como puede apreciarse de los anteriores ejemplos, esta forma de pensar presume que lo que gana la una parte (A) es perdido por la otra (B). Entonces, la suma de la Ganancia de A $\left(G_{A}\right)$ más la Pérdida de B $(P B)$ (que al ser negativa es propiamente $-P B$ ) es cero, como sigue:

$$
\left(G_{A}\right)+\left(-P_{B}\right)=0
$$


Por ejemplo, si en un negocio entre un comprador $\mathrm{A}$ y un vendedor $B$, el primero gana 10 (resultado $A=+10$ ), se concibe, por definición, que el resultado para $\mathrm{B}$ es menos 10 (resultado $B=-10$ ), y la suma algébrica de los dos resultados es cero:

$$
+10+(-10)=0
$$

\section{Elementos cognitivos (II)}

Pensamiento "suma positiva"

Existe otra forma de pensar respecto de los posibles desenlaces de una situación o relación, que propiamente tendría que describirse como "pensamiento suma positiva o negativa", pero que, como explico más adelante, considero apropiado llamar simplemente "suma positiva". Esta segunda forma de pensar concibe no dos, sino cuatro posibles desenlaces de una relación bilateral. Primero, los mismos dos que contempla el pensamiento "suma cero":

\section{Gana A y Pierde B (G,P)}

Gana $B$ y Pierde A $(P, G)$

Pero además, dos otros:

Gana A y también Gana B (G,G)

Pierde A y también Pierde $\mathrm{B}(\mathrm{P}, \mathrm{P})$

En el caso en que ambas partes ganan (G,G), el resultado para cada una de las partes es positivo (por ejemplo, resultado $A=+10$ y resultado $B=+10$ ), y la suma algébrica de los resultados es obviamente positiva:

$$
+10+(+10)=+20
$$

En el caso en que ambas partes pierden (P,P), el resultado para cada una de las partes es negativo (por ejemplo, resultado $A=-10$ y resultado $B=-10$ ), y la suma algébrica de los resultados es obviamente negativa:

$$
-10+(-10)=-20
$$

En vista de que esta forma de pensar contempla que la suma algébrica de los resultados puede ser o positiva o negativa, sería apropiada denominarla "pensamiento suma positiva o negativa". No obstante, los efectos de esta forma de pensar emanan principalmente del hecho que contempla el posible desenlace (G,G), es decir, un desenlace positivo para ambas partes, siendo la posibilidad de un desenlace (P,P) más bien algo a ser evitado y, como resultado, un incentivo para buscar (G,G). En consecuencia, propongo que la denominación "suma positiva" es suficiente para este modo de pensamiento

\section{Presentación gráfica}

Resulta útil presentar lo arriba expuesto de la siguiente manera:

El pensamiento "suma cero" puede representarse con dos personas, A y B, ubicadas en los extremos opuestos de una línea recta, que representa uno o más bienes (territorio, comida, agua, felicidad, etc.) que están disponibles para ambas:

$$
\text { A }
$$$$
\text { B }
$$

El desenlace de la relación, situación o conflicto (la "distribución" entre las partes) puede indicarse con un punto " $x$ " en la línea:

$$
\text { A }
$$

Bajo el esquema "suma cero", se entiende, como se indicó más arriba, que lo que "gana" la una parte es lo que "pierde" la otra

Ganacia de $\mathrm{A}=$ (tramo $\mathrm{A}-\mathrm{x})=$ Pérdida de $\mathrm{B}$

Ganacia de B = (tramo B-x) $=$ Pérdida de A

Si el desenlace es más favorable a $\mathrm{A}$, el punto " $x$ " se movería más hacia A:
A B

Si el desenlace es más favorable a $\mathrm{B}$, el punto " $x$ " se movería más hacia $B$ :

A

El pensamiento "suma positiva" puede representarse en un diagrama bi-dimensional en cuyo eje vertical se representa la satisfacción o "ganancia" de la parte A, y en cuyo eje horizontal se representa la satisfacción o "ganancia" de la parte B, como sigue:

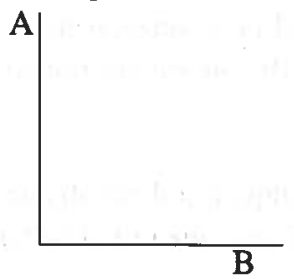

Pueden darse las siguientes resoluciones, que se indican en cada caso con una " $x$ ":

(a) A logra plena satisfacción de sus necesidades y $B$ no logra ninguna satisfacción de las suyas $(A=100$, $\mathrm{B}=0$ ):

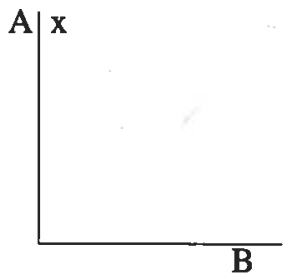

(b) A no logra ninguna satisfacción de sus necesidades y $B$ logra plena satisfacción de las suyas $(A=0$, $B=100$ ):

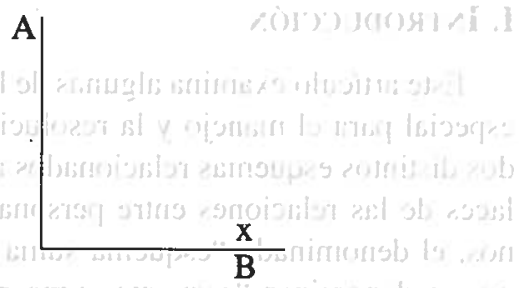

(c) A y B logran plena satisfacción de sus necesidades $(A=100, B=100)$ :

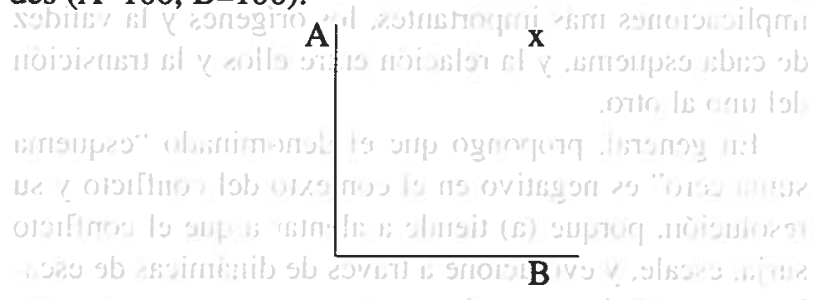

Este último gráfico que presenta el desenlace $(A=100, B=100)$ manifiesta con meridiana claridad la esencia del esquema "suma positiva": contempla la posibilidad de que se satisfagan las necesidades o aspiraciones de ambas partes, simultáneamente.

Elementos no cognitivos: más allá de sólo el "pensamiento"

Hasta acá se ha planteado la diferencia entre el uno y el otro esquema en términos de "formas de pensar", es decir, como elementos netamente cognitivos y analíticos. El plantemiento ha sido que existen dos diferentes esquemas cognitivos, o teorías, acerca del posible desenlace de situaciones o relaciones, entre las cuales las personas escogemos.

No obstante, como ya se señaló, existen otros elementos sicológicos vinculados, aparte de ese elemento neta- 
mente cognitivo que representan las palabras "pensamiento" o "forma de pensar". Estos otros elementos son sentimientos $\mathrm{o}$ actitudes y comportamientos.

Planteo que una persona $A$ puede tener sentimientos o actitudes "suma cero" o "suma positiva", en determinado momento y situación, en relación con determinada persona o grupo $B$, entendido "un sentimiento o una actitud suma cero" como un sentimiento en A de rechazo hacia B que conduce a que las necesidades, aspiraciones $\mathrm{e}$ intereses de B carezcan de importancia para A. Por el contrario, entiendo "un sentimiento o una actitud suma positiva" como un sentimiento en A de inclusión, entre sus necesidades, aspiraciones e intereses, de los de B. Planteo, además, que una persona puede experimentar sentimientos 0 actitudes "suma cero" o "suma positiva" independientemente de si esa persona se suscribe al pensamiento suma cero o al pensamiento suma positiva. Dos de los posibles casos parecen lógicamente contradictorios (pensamiento "suma cero" con actitudes "suma positiva", y pensamiento "suma positiva" con actitudes "suma cero"), pero la contradicción lógica, como muchas otras, no es imposible para la mente humana. Toda persona que se suscribe al pensamiento "suma positiva", pero que en determinado momento haya sentido ira, rechazo, deseo de lastimar a otra persona ha experimentado esa contradicción. También la ha experimentado toda persona que, suscribiéndose al pensamiento "suma cero", haya sentido el deseo de cuidar y proteger a otra persona, o cooperar y compartir con ella. Los afectos, las lealtades, las dependencias, la satisfacción mutua de necesidades y otros tipos de lazos entre las personas generan múltiples motivos por los cuales éstas puedan sentir, afectivamente, algo que pueda ser contrario a lo que piensen cognitivamente.

Planteo también, bajo un razonamiento similar, que una persona puede mostrar comportamientos "suma cero" que se manifiestan en que una persona $A$ por ejemplo tome para sí lo que necesite (por ejemplo de comida, de agua, etc.) negándole o quitándole a otra persona $B$ lo que B necesite. Una frecuente manifestación de comportamiento "suma-cero"s se da cuando una diferencia de gustos, opiniones o criterios se convierte en una confrontación personal que las partes buscan resolver por la vía de la imposición, es decir, llevando la disputa al terreno "suma-cero" de "o te gano la discusión, o me la ganas tú". Este tipo de confrontación puede ser causada tanto por condiciones sicológicas de las personas involucradas como por la ampliamente difundida (y a mi juicio equivocada) creencia de que para todo tipo de problema o situación existe "la solución correcta" que no solo puede ser impuesta, sino que debe serlo. Como en el caso anterior, planteo que es posible tal comportamiento de parte de una persona, independientemente tanto de sus pensamientos como de sus sentimientos al respecto: nuevamente, no obtsante la inherente contradicción lógica, es posible que una persona A se declare convencida del pensamiento "suma positiva", tenga sentimientos "suma positiva" hacia otra persona $\mathrm{B}, \mathrm{y}$, sin embargo, muestre comportamiento "suma cero".

\section{CONSECUENCIAS DE UNO Y OTRO ESQUEMA}

Consideraciones iniciales

Independientemente de las demás influencias ${ }^{2}$ que operan sobre las personas, puede razonablemente afirmarse que aquellas que actúan bajo la influencia del esquema suma cero tienen una mayor tendencia a verse envueltas en conflictos, a encararlos de manera contenciosa, a que, en consecuencia, sus conflictos escalen, a que el escalamiento de su conflictos alcance mayores niveles, y a que sea más difícil su desescalamiento y eventual resolución de sus conflictos. Para fundamentar este conjunto de afirmaciones, examinaré a continuación las influencias de los esquemas "suma cero" y "suma positiva", sobre el inicio mismo de conflictos, la selección de una estrategia para abordarlos, los procesos de escalamiento del conflicto, en especial a través de los denominados "cambios estructurales", los procesos de desescalamiento y los procesos la resolución negociada de conflictos.

Algunas de estas influencias son ejercidas directamente, y otras lo son indirectamente, a través de efectos sobre el desarrollo de la personalidad y el crecimiento sicológico y emocional de las personas, que a su vez incide en las relaciones afectivas y de confianza entre personas. Comenzaremos por la exploración de estos efectos sicológicos indirectos.

\section{Efectos sobre el desarrollo y la estructura sicológica}

El sano desarrollo sicológico y emocional de una persona humana incluye, importantemente, la disolución de los denominados "lazos primarios" de dependencia, típicamente (aunque no sólo) con la madre y el padre, y el logro de independencia sicológica y emocional, en base a la cual la persona es luego capaz de establecer "lazos secundarios" sanos y fecundos de interdependencia, confianza y amor ${ }^{3}$. Si, por el contrario, la persona no logra desarrollar esa independencia sicológica y emocional, se vuelve susceptible de caer en varias diferentes formas de escapismo y de verse envuelta en relaciones interpersonales de tipo dominio-sumisión, sin jamás poder satisfacer adecuadamente la necesidad humana más básica de todas, que, a decir de Fromm, es responder al sentido de "separatidad o estado de separación"4.

Planteo que el esquema de creencias, sentimientos y comportamientos "suma cero" puede tender a influir en contra del desarrollo sicológico y emocional sano. Si, en el transcurso de su desarrollo, una persona concibe que las únicas opciones de posible desenlace de las relaciones y situaciones de su vida son "o gano o pierdo", o desarrolla sentimientos y actitudes excluyentes de las necesidades de otros, y/o se comporta de manera que sólo privilegia las propias necesidades 0 aspiraciones, es razonable pensar que tenderá a vivir en condiciones de relativa privación afectiva, antes que en condiciones de afecto, interdependencia y confianza con otros.

La presencia de fuertes lazos afectivos y la consecuente sana intedependencia y confianza inciden de tres maneras en la evolución y resolución de conflictos: primero, tienden a que surjan menos conflictos entre las personas; segundo, si llega a surgir un conflicto, este tiene menos tendencia al escalamiento; y tercero, si el conflicto llega a escalar, tiende a hacerlo bajo una dinámica más antes que menos benigna. En los párrafos siguientes, examino en mayor detalle estas tres proposiciones.

Los lazos afectivos fuertes y la confianza enre las personas estimulan el desarrollo de valores, necesidades y 
aspiraciones comunes, antes que divergentes e incompatibles. Partiendo de la forma de entender "conflicto" propuesta por Jeffrey $Z$. Rubin, quien sugiere que debe entenderse como "aquella situación en que las aspiraciones de dos o más partes son incompatibles en un mismo momento", todo aquello que reduce la incompatibilidad de aspiraciones, incluidos lazos de afecto, confianza e interdependencia, reduce la posibilidad misma de que surjan conflictos.

Los conflictos, sin embargo, surgen, aun entre personas unidas por los más fuertes y sinceros lazos de afecto y confianza. Una vez que hubiere surgido un conflicto entre esas personas, existe amplia evidencia de que el deseo de conservar y mantener la calidad de la relación influye para evitar o atenuar el escalamiento del conflicto, que es aquel proceso a través del cual este se vuelve más pesado, áspero, contencioso, hostil y potencialmente destructivo.

Por último, aún si un conflicto entre personas unidas por fuertes lazos afectivos y de confianza llega a escalar, existe también amplia evidencia de que la presencia de esos lazos tiende a que el escalamiento siga una dinámica más leve, generando estados sicológicos temporales, como la ira y el temor, que tienden a revertirse por sí mismos, antes que una dinámica de escalamiento más profunda que genere los denominados "cambios estructurales", cuyas máximas expresiones son la deshumanización y la demonización de la otra parte y una de serie de mecanismos sicológicos autoconfirmatorios que tienden a la permanencia o "perpetuación" del escalamiento en el tiempo y en su intensidad.

En resumen, al influir negativamente sobre la voluntad y eventual capacidad para establecer lazos fuertes de afecto y confianza, el esquema "suma cero" puede incidir en una mayor propensidad al conflicto, una mayor propensidad a que este escale, y en la profundidad y destructividad de su potencial escalamiento. Las influencias del esquema "suma positiva" son exactamente las contrarias, reduciendo la posibilidad de incompatibilidad entre las partes y la voluntad de utilizar tácticas contenciosas du$\operatorname{ras}^{6}$.

\section{Influencias sobre la elección de una estrategia para abordar un conflicto}

En breve resumen, se reconocen tres estrategias para abordar un conflicto? : (a) la cesión sistemática, que consiste en sacrificar la satisfacción de las propias necesidades y aspiraciones y dejar que la otra parte en un conflicto logre la satisfacción de las suyas; (b) la estrategia contenciosa, que, al contrario de la estrategia de cesión, consiste en tratar de imponer sobre la otra parte la satisfacción de las propias aspiraciones, sin perjuicio de cualquier consecuencia negativa que esto pueda traer para la otra parte; y (c) la búsqueda de resolución del conflicto, que consiste en intentar la satisfacción de por los menos algunas si no todas las aspiraciones de ambas partes. Una cuarta posible postura frente al conflicto es el evitamiento, que se distingue de las otras tres por el hecho de no ser, por definición, una estrategia para abordar el conflicto, sino más bien una estrategia para no abordarlo.

Los esquemas "suma cero" y "suma positiva" influyen de manera significativa sobre la elección de una estrategia de abordamiento, según exploro a continuación.
El esquema "suma cero" tiende sobre todo a alentar la elección de una estrategia constenciosa por dos motivos principales. Primero, en el nivel cognitivo, si una de las partes o ambas entienden que sólo existen las dos opciones $(G, P)$ o $(P, G)$, es razonable pensar, salvo casos excepcionales que examino más abajo, que la tendencia más frecuente será la de tratar de ser la parte que "gana". Esta puede ser la conclusión por varios posibles motivos, incluidos alta auto-estima; rigidez o baja renunciabilidad de aspiraciones, basada en su alta importancia, típicamente asociada con el deseo de satisfacer necesidades básicas como la supervivencia, la seguridad, la identidad, y otras; la percepción de propia fuerza relativa a la percibida debilidad de la otra parte; independencia respecto de la otra parte; y/o poco interés en la conservación de buenas relaciones con la otra parte. Segundo, en el nivel afectivo, si los sentimientos y actitudes de una de las partes o de ambas son "suma cero", no habrá interés ni deseo de buscar caminos a la satisfacción de las necesidades o aspiraciones de la otra parte, y, por el contrario, habrá una tendencia a pensar sólo en las dos opciones "suma cero" y en el deseo de imponer la opción (G,P).

El aliento a la elección de una estrategia contenciosa, según el razonamiento del párrafo anterior conlleva por definición el desaliento de la elección de una estrategia de resolución. El objetivo de esta segunda estrategia, que es un desenlace mutuamente satisfactorio, ni siquiera es contemplado como posible bajo el pensamiento "suma cero". Cuanto más consciente es la elección de estrategia, más va a pesar el componente netamente cognitivo del esquema "suma cero", el pensamiento, la idea que no existe posibilidad de satisfacción mutua. Si la elección de estrategia es menos consciente, un sentimiento o una actitud "suma cero" hacia la otra parte puede tener el efecto similar de desalentar la elección de una estrategia de resolución porque, para la parte que va a elegir una estrategia, las necesidades, los intereses y las aspiraciones de la otra parte en conflicto carecen de importancia, y, por el contrario, sí tienen importancia los propios sentimientos de hostilidad y venganza hacia la otra parte.

El esquema "suma cero" puede, en determinadas circunstancias especiales, alentar a una de las partes en un conflicto a elegir una estrategia de cesión. Entendiendo que sus opciones de desenlace son o $(\mathrm{G}, \mathrm{P})$ o $(\mathrm{P}, \mathrm{G})$, puede decidir buscar la opción (P,G), es decir "yo pierdo, tu ganas" a causa de una baja auto-estima y la consecuente baja valoración de las propias aspiraciones; una relativamente menor rigidez de aspiraciones porque no se consideran de gran importancia; la percepción de propia debilidad en relación con el poder de la otra parte; y dependencia respecto de la otra parte.

Al contrario de lo planteado en los párrafos inmediatos anteriores, la influencia del esquema "suma positiva" tiende a alentar la elección de una estrategia de resolución y a desalentar la elección de estrategias contenciosas. Si las partes reconocen que una de sus opciones es la satisfacción simultánea de las necesidades y aspiraciones de ambas partes (pensamiento "suma positiva"), o si están presentes en su proceso de decisión sentimientos o actitudes "suma positiva", existen claras y fuertes influencias a favor de la elección de una estrategia de resolución y en contra de una estrategia contenciosa. 
Influencias sobre procesos de desescalamiento de conflictos cuyo escalamiento ha tendido a perpetuarse

Cuando un conflicto nace, puede seguir uno de tres posibles caminos: (a) es materia inmediata de negociación y resolución; (b) entra en un proceso de escalamiento temporal, que tiende a desescalamiento a corto plazo sin dejar mayores residuos; $o$ (c) entra en otro tipo de escalamiento más severo, que conduce a los denominados "cambios estructurales" que conllevan imágenes y actitudes altamente negativas entre las partes, y que tienden a la denominada perpetuación, que es la tendencia a la permanencia del escalamiento.

En el tercero de estos casos, en que el escalamiento de un conflicto ha tendido a perpetuarse, surgen dos posibles influencias de los esquemas "suma cero" o "suma positiva". La primera influencia se da en relación con posibles movimientos, de una u otra parte en el conflicto, o de ambas, en dirección a buscar desescalar y eventualmente resolver el conflicto. La segunda influencia se da en el contexto de procesos denominados "pre-negociación". A continuación exploro cada uno de estos dos casos.

En primer lugar, pueden con el tiempo surgir factores que abran la posibilidad, en las mentes de las partes en un conflicto que ha escalado y se ha perpetuado, de buscar el desescalamiento y la eventual posible resolución del conflicto. Estos factores incluyen, típicamente, la merma de los recursos disponibles y las energías necesarias para mantener el conflicto en su condición de escalamiento perpetuado, y la percepción de posibles beneficios mutuos de un desescalamiento ${ }^{8}$. Un ejemplo claro de esto último se dio en el reciente proceso de desescalamiento y conclusión de acuerdos que pusieron fin al conflicto limítrofe entre Ecuador y Perú, proceso que fue motivado, al menos en parte, por la percepción de que ambos países podrían beneficiarse con la reducción de sus respectivas inversiones en capacidad bélica, el aprovechamiento conjunto de recursos hídircos, mejores posibilidades de inversión extranjera, posible incremento del comercio bilateral, etc.

El que dos partes en conflicto, como el Ecuador y el Perú en el ejemplo, puedan reconocer y luego actuar conjuntamente para lograr tales potenciales beneficios mutuos depende directamente de que ambas partes tengan una visión "suma positiva". Si la visión de las partes es "suma cero", la merma de recursos y energías por sí sola es frecuentemente insuficiente para estimular a las partes a comenzar un proceso de desescalamiento y eventual resolución del conflicto. Una visión "suma positiva", que admite la posibilidad de satisfacción de las necesidades y aspiraciones de ambas partes, parece imprescindible para que las partes decidan buscar los potenciales beneficios mutuos del desescalamiento y la resolución de su conflicto.

En segundo lugar, existen conflictos en los que las partes por sí solas no logran vencer la inercia del escalamiento y la perpetuación de su conflicto. En estos casos, de los cuales un claro ejemplo es el conflicto israelí-palestino, resulta de fundamental utilidad, y hasta llega a parecer imprescindible, la intervención de una tercera parte imparcial que convoque a las partes a lo que en general se describe como un proceso "pre-negociación", en el cual la tercera parte busca estimular una comunicación altamen- te estructurada entre las partes tendiente a que cada una de ellas comprendan la perspectiva, las necesidades, los temores y las aspiraciones de la otra, hasta llegar a lo que la máxima autoridad en el tema a nivel mundial, Herbert $C$. Kelman decribe como "la realización de que el conflicto es un dilema compartido" ". Para el éxito de este tipo de proceso "pre-negociación", es, nuevamente, esencial el que las partes en conflicto tengan, en alguna medida, tanto pensamientos como sentimientos "suma positiva". En tanto ambas estén dominadas por el esquema "suma cero", es razonable pensar que el logro que plantea el Profesor Kelman no sea buscado ni pueda ser alcanzado por las partes.

\section{Influencias sobre la resolución negociada de un} conflicto

Cuando las partes en un conflicto llegan a la mesa de negocación, la cual por definición consiste en la búsqueda conjunta de un acuerdo resolutorio, sea que lleguen directamente porque el conflicto nunca escalo, o lleguen, finalmente, al término de procesos de desescalamiento como los descritos en los párrafos anteriores, es evidente la necesidad de que ambas estén animadas por una visión "suma positiva" de sus opciones y por sentimientos y actitudes "suma positiva" respecto de la parte contraria para que puedan llegar a una resolución mutuamente satisfactoria. Si, por el contrario, las partes en una negociación están imbuidas del esquema "suma cero", estarán entrampadas en una concepción de sus posibles opciones y un conjunto de sentimientos y actitudes que impiden la esencia de la negociación exitosa, que es, precisamente, la búsqueda de una o más opciones que satisfagan las aspiraciones, los intereses y las necesidades de ambas partes. La denominada "negociación por principios", cuyos máximos proponentes teóricos son Roger Fisher y William Ury ${ }^{10}$, resulta imposible de aplicar, en realidad, en ausencia de una visión de posibles desenlaces que incluya la opción de satisfacción mutua (G,G), y actitudes y comportamientos coherentes con esa visión

\section{LOS DOS ESQUEMAS Y LA HISTORIA DE LA RE- SOLUCIÓN DE CONFLICTOS}

\section{Tres formas de buscar el desenlace o la resolución}

Ury, Brett y Goldberg " plantean una forma de entender la evolución de la resolución de conflictos en las sociedades humanas que resulta de enorme interés en el contexto del presente análisis. De acuerdo con estos autores, pueden identificarse tres modos de aproximación ("approaches") a la búsqueda de desenlace o resolución ${ }^{12}$ de un conflicto: en base al poder, con base en los derechos relativos de las partes, o en base a la conciliación de sus necesidades e intereses.

\section{Una perspectiva histórica}

Resulta interesante colocar el planteamiento de Ury, Brett y Goldberg en una perspectiva histórica. Durante los primeros varios millones de años de la existencia de nuestra especie, el único camino que se conocía y aplicaba para tratar de zanjar una disputa era apelar al poder, en cuyo caso el desenlace era casi siempre favorable al más fuerte. Incluso en los casos de excepción en los que parecería haber prevalecido el menos "fuerte", como el de 
David y Goliat, habría que cuestionarse no cual de los dos era más "fuerte", sino en que consistía la "fuerza" relativa.

Progresivamente, las comunidades humanas fueron desarrollando mecanismos más racionales de formulación y aplicación de la normativa social, $y$, desde hace unos ocho a nueve mil años ha estado claramente presente en el desenvolvimiento de nuestras sociedades el concepto del derecho. No es que se hubiese abandonado el recurso a la fuerza, como bien sabemos. Al contrario, poniendo en evidencia la notable renuencia que a mi juicio caracteriza a nuestra especie a abandonar viejos paradigmas una vez que hubieran aparecido nuevos, más útiles y más lógicamente defensibles, seguimos apelando a la fuerza bruta en disputas desde domésticas hasta internacionales con alarmante facilidad. Incluso, es evidente que el recurso al poder y el recurso al derecho no constituyen dos opciones del todo mutuamente excluyentes, en por 10 menos dos sentidos. Por un lado, puede darse la resolución en derecho de una disputa, y luego hacerse necesaria la aplicación del poder (policial u otro) para hacer cumplir esa resolución en derecho. Por otro lado, el derecho no siempre ha sido, ni es, en algunas sociedades, igual para todos. Filmer S.C. Northrop pone en evidencia la influencia conjunta de poder y de derecho y la evolución de esa compleja relación al describir lo que llama la transición de un sistema de 'derecho por status' a un sistema de 'derecho puro' o de 'derecho contractual': comenta que en la Inglaterra del siglo XIV, si un conde y un campesino hubiesen ido en busca de la justica del Rey en una disputa por la propiedad de un trozo de tierra, el Rey habría fallado en favor del conde porque era conde y poderoso, pero que si los descendientes de ambos litigantes fuesen a presentar la misma disputa, hoy, ante un tribunal de justicia, el tema se decidiría a base de los derechos de cada parte y los méritos de sus respectivas causas ${ }^{13}$. No obstante la injerencia del poder en la aplicación del derecho, el concepto mismo del derecho introdujo en las sociedades humanas una segunda opción, una manera alterna, potencialmente menos destructiva, de buscar el desenlace de una disputa.

El cambio que describe Northrop constituye a mi juicio un notable progreso desde dos puntos de vista: primero, en el terreno del manejo y la resolución de conflictos, considero de inmenso valor el que existan los mecanismos judiciales, a través de los cuales se pueda intentar dirimir disputas de manera objetiva y no violenta; y segundo, en el terreno de la ética social, considero de inmenso valor la progresiva afirmación de la igualdad de derechos de todo ser humano. Toda persona, desde Hammurabi y los primeros abogados romanos hasta los abogados y profesores de derecho del presente, que han contribuido a que los seres humanos vivamos en sociedades regidas, aunque sea imperfectamente, por la ley y el derecho tienen legítimo motivo de satisfacción.

\section{Conexión con "suma cero" y "suma positiva"}

Sin embargo, al conectar ese breve análisis histórico con el tema principal de este artículo, que es el de los esquemas "suma cero" y "suma positiva", podemos ver que tanto el modo de buscar desenlace a las diputas más antiguo y hasta 'primitivo' de apelar al poder, como el más 'civilizado' de apelar al derecho, son sistemas cuyos desenlaces son "suma cero": una de las partes gana y la otra pierde. En este sentido, es factible interpretar a ambos modos como expresiones de una misma larga tradición contenciosa de la humanidad. Podemos preferir, legítimamente, creo, el segundo sistema: parece más atractivo, en términos de ética social, poder decir "ganó porque tiene razón, o porque tiene derecho" que tener que decir "ganó porque es el más fuerte", pero sigue siendo cierto que estamos diciendo, aún entonces, "él ganó, y el otro perdió".

Es en estos términos que adquiere su mayor importancia el hecho de que en las últimas décadas ha comenzado a tener presencia significativa en las sociedades humanas la tercera opción - la búsqueda de la resolución de disputas sobre base de la conciliación de las necesidades y aspiraciones de las partes. Se ha introducido una novedad revolucionaria en términos conceptuales, éticos y espirituales. Hasta donde conozco - y el tema es de suficiente importancia como para merecer una cuidadosa y sistemática investigación - esta tercera forma de aproximarse a la búsqueda del desenlace y de la resolución ${ }^{14}$ de disputas no se ha visto antes en la historia de la humanidad. Por primera vez, a partir de las últimas décadas, los seres humanos hemos logrado formular esquemas para abordar y resolver nuestros conflictos que propendan a desenlaces "suma positiva".

Es importante no caer en excesivo optimismo al respecto. Estos esquemas no son fórmulas mágicas. Hay múltiples limitantes reales a su aplicabilidad, entre las cuales la primera que debe reconocerse es que, sin perjuicio del conjunto de fenómenos sicológicos que entrañan los esquemas "suma cero" y "suma positiva", hay situaciones que objetivamente son "suma cero". Por ejemplo, si dos personas han venido cruzando el desierto del Sahara en direcciones opuestas, habiendo cada una perdido sus reservas de agua, y en el momento de encontrarse, a medio desierto, encuentran también una pequeña botella con agua suficiente para salvar la vida de la una o la otra, pero no las vidas de ambas, la situación en sí es "suma cero", independientemente de si ambas personas piensan, sienten o desean actuar bajo el esquema "suma positiva". Los nuevos enfoques "suma positiva" orientados a la conciliación de necesidades y aspiraciones también chocan contra realidades sico-sociales, tales como creencias religiosas, valores éticos, relatos étnicos, históricos y culturales, que forman parte esencial de la identidad y el sentimiento de seguridad de los pueblos, y en consecuencia son muy difíciles de someter a posible renunciamiento, aunque fuese parcial, en aras de resoluciones pragmáticas "suma positiva". Esas y otras limitaciones no obstante, en las últimas décadas hemos podido presenciar una creciente serie de procesos de paz que, aun en su imperfección y fragilidad, no dejan de ser asombrosos. Entre estos cabe mencionar el proceso de paz árabe-israelí e israelí-palestino, la transferencia pacífica del poder político de la minoría blanca a la mayoría negra en Sudáfrica, el fin de las guerras de insurgencia en América Central, y el más reciente y más frágil de todos, el proceso de paz en Irlanda del Norte.

\section{Un ejemplo}

Existe, dentro del contexto del conflicto israelí-palestino, un vívido ejemplo de consciente retiro del esquema "suma cero" y àdopción del esquema "suma positiva", que tanto por su transcendencia histórica como por la claridad con que permite ilustrar esa transición, merece ser 
examinada con detenimiento. En un artículo publicado en 1978 en la revista Foreign Affairs, el prominente pensador palestino Wálid Khalidi comienza por plantear la necesidad de que "el conflicto Árabe-Israelí sea abordado con realismo" "' Más adelante, señala que varios desarrollos estructurales, incluidos el colapso de la República Árabe Unida, la muerte de Nasser y el desarrollo en los países árabes de una élite tecnocrática, orientada al desarrrollo "han contribuido a la generación de un espíritu de mucho mayor pragmatismo respecto de las relaciones regionales y globales, incluso el conflicto Árabe-Israelr?" ${ }^{16}$ Agrega luego ${ }^{17}$ :

La posibilidad de que este nuevo modelo para el sistema de los estados Árabes prevalezca sobre el existente modelo florido y apocalípitico depende principamente de si es posible una honrosa resolución total del Problema Palestino y, en consecuencia, del conflicto Árabe-Israelí.

¿Cual fué su propuesta para esa "honrosa resolución"? Khalidi fue el primer prominente palestino en proponer la partición de los territorios en disputa y la creación de un Estado palestino soberano. Esta idea, tal vez inocua a ojos del lector contemporáneo, constituía un radical rompimiento con la entonces generalizada opinión Palestina y Árabe. Como el propio título del artículo de Khalidi lo sugiere, constituía "pensar lo impensable". Nuevamente, cito al propio Khalidi ${ }^{18}$ :

La opinión (general) Palestina y Árabe aspiraba a la recuperación de todo el territorio Palestino y el establecimiento de un estado democrático y secular en él. Aceptar la idea de una partición y de un estado (Palestino) en la margen occidental (del Río Jordán) y la Franja de Gaza era traición. En algunos círculos Palestinos y Árabes, lo sigue siendo... (Pero) es el desarrollo largamente esperado por observadores externos y por los Israelíes. Sería trágico no reconocerlo ahora que ha comenzado a ocurrir, y sería aún más trágico si fuese reconocido pero ignorado.

Por supuesto que la opinión general palestina y árabe rechazó encendidamente esta propuesta de Khalidi. Muchos le llamaron traidor, y su vida corrió peligro. Su propuesta implicaba renunciamientos importantes a creencias, valores $y$ reivindicaciones de altísimo contenido afectivo, que atañían al sentido mismo de identidad del pueblo palestino. Pero el argumento central de Khalidi, que con el tiempo vino a ser descrito como el de la "justicia pragmática", era que si los dos pueblos, el Palestino y el Israelí, se aferraban cada uno a la validez exclusiva de su relato histórico, su sentido de la verdad, su derecho y su razón, en lugar de buscar la conciliación pragmática de las necesidades y las aspiraciones de ambos pueblos, el conflicto jamás podría ser resuelto. Puesto en los términos principales de este artículo, lo que Khalidi planteaba era pasar de una visión "suma cero" a una visión "suma positiva" del conflicto y de su posible resolución.

Al lector no le es desconocido el dilema moral y afectivo que planteó Khalidi. Es similar al que plantearon para la sociedad ecuatoriana las propuestas de resolución del conflicto limítrofe con el Perú. También en el Ecuador, la sola idea de buscar una solución pragmática al conflicto basada en un esquema "suma positiva" ha constituido para muchos, y constituye aún para algunos, "pensar lo impensable". Los valores de identidad nacional, honor y tradición histórica son valores del más alto nivel. El duro y dramático dilema viene porque también lo son los valores de la paz, la cooperación entre los pueblos, la dedicación de recursos escasos a otros fines distintos del poderío bélico.

El problema de si es o no moral y políticamente válido, en determinada circunstancia histórica, hacer algún tipo de renunciamiento a ciertos altos valores en favor de los valores de la paz y el evitamiento de la destructividad de la guerra es, y será siempre, un problema de juicios de valor, respecto de los cuales es improbable que jamás lleguemos todos a pensar de igual manera. Puedo además reconocer condiciones en las que, no obstante el dolor y la destructividad que implique, pueda ser preferible el conflicto escalado antes que la paz. En lo que sí creo que es factible llegar a general acuerdo es en que, en la medida en que se nos hace factible replantear nuestras prioridades valorativas, hasta "pensando lo impensable", para poder ver un conflicto bajo el esquema "suma positiva", en vez de verlo bajo el esquena "suma cero", serán mucho mayores las posibilidades de evitar mayor escalamiento y perpetuación del conflicto y las de poderlo desescalar y eventualmente resolver.

Hay otros ejemplos como el de Wálid Khalidi. Anwar Sadat rompió con la hostilidad implacable de los árabes hacia los israelíes, visitó Jerusalén y dio la mano a los judíos que lo recibieron', propiciando, con todos estos notables cambios hacia el esquema "suma positiva", el eventual acuerdo de devolución del Sinaí y la normalización de relaciones diplomáticas entre Egipto e Israel. Nelson Mandela, poniendo espléndidamente de manifiesto lo mejor del espíritu humano, salió de más de veinticinco años de cárcel en ánimo de negociar y conciliar, no de vengarse.

\section{AlgUNAS IMPLICACIONES, REFLEXIONES Y CONCLUSIONES}

Dentro de los límites razonables de este artículo en esta revista (comparados con los que podrían ser los límites, por ejemplo, de todo un libro dedicado al tema), no es posible señalar y reflexionar sobre todas las importantes implicaciones que surgen de lo planteado hasta acá. En consecuencia, he escogido reflexionar brevemente sobre sólo dos preguntas: (a) ¿Cual es la validez del uno y el otro esquema? y (b) Si alguno es más válido que el otro, ¿qué puede hacerse para estimular la mayor presencia del más válido en la realidad humana?

La validez del uno y del otro esquema

Para formular este juicio, creo que es necesario distinguir entre lo descriptivo, el terreno de lo que es, y lo normativo, el terreno de lo que considero que debe ser. En el terreno descriptivo, veo muchos motivos para reconocer la superior validez del esquema "suma cero": parece más real, más ajustado a lo que ocurre en la realidad humana. En el terreno normativo, por otro lado, estoy profundamente convencido de la superior validez del esquema "suma positiva".

Primero, en el terreno descriptivo, hay que preguntarse si, objetivamente, las relaciones interpersonales y los procesos sociales conducen a "suma positiva" efectiva, es decir, al real beneficio mutuo de las partes involucradas en las múltiples situaciones y relaciones de la vida diaria. 
La respuesta honesta, por mucho que nos duela o moleste, es que, salvo muy escasas excepciones, los resultados de esas relaciones y esos procesos tienden a ser "suma cero". En las relaciones interpersonales, los seres humanos experimentan con penosa frecuencia la imposición del más fuerte en relaciones de dominio-sumisión: el padre que ordena al hijo a hacer algo "porque yo digo", el profesor que obliga al estudiante a aceptar como equivocada una respuesta correcta, el sacerdote que consigue favores so pena de no conceder una absolución, el empleador que obliga al empleado a trabajar más horas por menos paga, el esposo o la esposa que somete a su pareja a chantaje emocional con la amenaza de quitarle su cariño o su apoyo, y, en un nivel más desnudo, el asaltante a mano armada o el violador a punta de cuchillo. En el ámbito social, la vasta mayoría de nosotros ha estado y aún está expuesta a procesos políticos de diversos matices ideológicos y formales cuyo supuesto fin es la búsqueda del bien común, pero cuyo verdadero fin parece ser la captación del poder y la consecuente capacidad para cometer abusos, ya no sólo a nivel interpersonal, sino en mayor escala y sobre un escenario más grande. No debe sorprendernos que la experiencia destilada de miles de años haya hecho comunes en la humanidad ciertas creencias que, sin estar, en la mayoría de mentes, en el nivel conceptual de marcos teóricos detalladamente estructurados, y sin que, en consecuencia, quienes están bajo su influencia puedan verbalizarlas o atribuirlas a sus autores, están de todos modos ampliamente presentes, reforzando en el ámbito popular lo que la experiencia personal y social tiende a sugerir a la mayoría de personas. Entre estas creencias podemos contar la frase de San Agustín de que "el hombre es lobo del hombre"; su variación Hobbesiana, que torna "natural" el corrompido estado de la mayoría de sistemas políticos en el mundo; la equivocada teoría marxista de la plusvalía; la teoría leninista del imperialismo y muchas otras.

Del otro lado, es muy clara para mí la superior validez normativa, en casi toda situación, del esquema "suma positiva". La influencia de pensamiento, actitudes y comportamientos "suma positiva" sobre la evolución y la eventual resolución de conflictos sociales, que ilustré extensamente más arriba, demuestra con claridad el principal fundamento para este juicio de valor en el terreno de la ética social. Además de esas consideraciones éticas, que son de primordial importancia para mí, hay a mi juicio consideraciones sicológicas, relacionadas a la posibilidad de generar mayor felicidad humana, que también sustentan de manera importante mi juicio de mayor validez normativa del esquema "suma positiva". Dicho esto, cabe aclarar la limimtación expresada con la frase "en casi toda situación" al inicio de este párrafo: como ya he expresado más arriba, reconozco situaciones en las que, incluso por motivos éticos, no cabe aplicar un esquema "suma positiva". Un caso de estos sería, para mí, aquel en el que uno encontrase a un violador intentando perpetrar su repugnante acto de violencia: resultaría absurdo proponerle, en ese momento, la búsqueda de "satisfacción de ambas partes". Excepto por tales límites, sostengo mi juicio de superior validez normativa del esquema "suma positiva" para toda otra situación.
¿Se puede estimular la presencia y vigencia del esquema "suma positiva"? ¿Si sí, cómo?

Pongo término a este artículo con algunas reflexiones sobre la posibilidad de que el esquema "suma positiva" se convierta en el esquema dominante para la especie humana, tanto en las relaciones interpersonales como en actividades sociales fundamentales tales como los procesos políticos, la administración de justicia, la resolución de conflictos y la educación.

Comienzo afirmando que creo firmemente que sí es posible estimular la presencia, la vigencia y hasta la preponderancia del esquema "suma positiva". Reconociendo claramente la fuerza de todas las influencias descritas más arriba que hacen que la realidad de la mayoría de personas tienda más bien, tristemente, a ser "suma cero", creo que la influencia de todos esos factores es susceptible de reversión, aunque sea parcial y gradual.

Infundir el esquema "suma positiva" en cada vez más personas y grupos humanos demandará, a mi juicio, atención prioritaria a tres cosas, muy relacionadas entre sí: (a) la difusion conceptual del contenido y las implicaciones de los dos esquemas, para que más y más personas hagan una elección consciente entre ellos, antes que la "adquisición" implícita de uno de ellos (que con mucha mayor frecuencia tiende a ser, hasta hoy, el esquema "suma cero"); (b) la consciente búsqueda, por aquellos de nosotros que ya estamos persuadidos de la validez de este esquema, de resoluciones "suma positiva" a nuestros conflictos interpersonales y sociales, comenzando con los más íntimos pero sin limitarnos a ellos - los conflictos de pareja, entre padres e hijos, entre hermanos; y (c) la progresiva resolución de los problemas sociales de marginalización, falta de oportunidades y generalizada insatisfacción de las necesidades humanas básicas de una enorme proporción de la humanidad.

La difusion conceptual que propongo debe hacerse a mi juicio tomando en cuenta que los esquemas que hemos venido examinando pertenecen a una clase de elementos que denomino "cimientos intelectuales" de la actividad humana, que son un conjunto de posturas, actitudes y creencias más implícitas que explícitas, y que en consecuencia tienen influencias de las cuales con frecuencia estamos escasamente conscientes sobre nuestras demás creencias, nuestros valores, nuestras actitudes y nuestros comportamientos. Es esa condición oculta y subterránea, pero a la vez fuertemente determinante de toda la estructura de nuestro ser, que dio origen al uso metafórico del concepto "cimientos" ${ }^{20}$. Estos "cimientos intelectuales" son típicamente adquiridos ${ }^{21} \mathrm{o}$ "recogidos" del medio ambiente cultural e intelectual desde la infancia, de manera poco o nada consciente, sin que medien ni la enseñanza (sea o no escolarizada) ni el aprendizaje formales, ni marcos teóricos o conceptuales explícitos. Esa condición de ser "implícitos" da a los cimientos intelectuales la apariencia de ser intuitivamente obvios y, en consecuencia, de ser verdades incuestionables. Son, como elementos intelectuales, prácticamente el opuesto exacto de conocimientos derivados del consciente y sistemático estudio y reflexión sobre un marco teórico y conceptual y del posterior procesamiento reflexivo de información puntual dentro de ese marco teórico. La principal implicación pa- 
ra el proceso de difusión conceptual que planteo es que no es ni remotamente suficiente la simple enunciación de las ideas relevantes. Se trata de primero desarmar los esquemas implícitos, a nivel de "cimientos" vigentes, para luego someter a consideración y reflexión los marcos conceptuales que este artículo presenta.

Para afrontar ese desafío, resulta altamente instructivo el análisis del cambio de paradigmas de Thomas Kuhn ${ }^{22}$, en especial su admonición de que los seres humanos comenzamos a abrimos a un posible cambio de paradigma solamente cuando el vigente comienza a fallarnos de ma- nera evidente. Coherente con ese argumento, propongo que debemos comenzar con demonstraciones patentes de las nefastas consecuencias del esquema "suma cero" en las relaciones de pareja, entre padres, madres, hijos e hijas, en los procesos políticos, en la educación, en todo orden de asuntos humanos. Si logramos que las personas se cuestionen ese esquema, estará sentada la primera base de una transición similar a aquella que hicieron, en su momento, Wálid Khalidi, Anwar Sadat y Nelson Mandela.

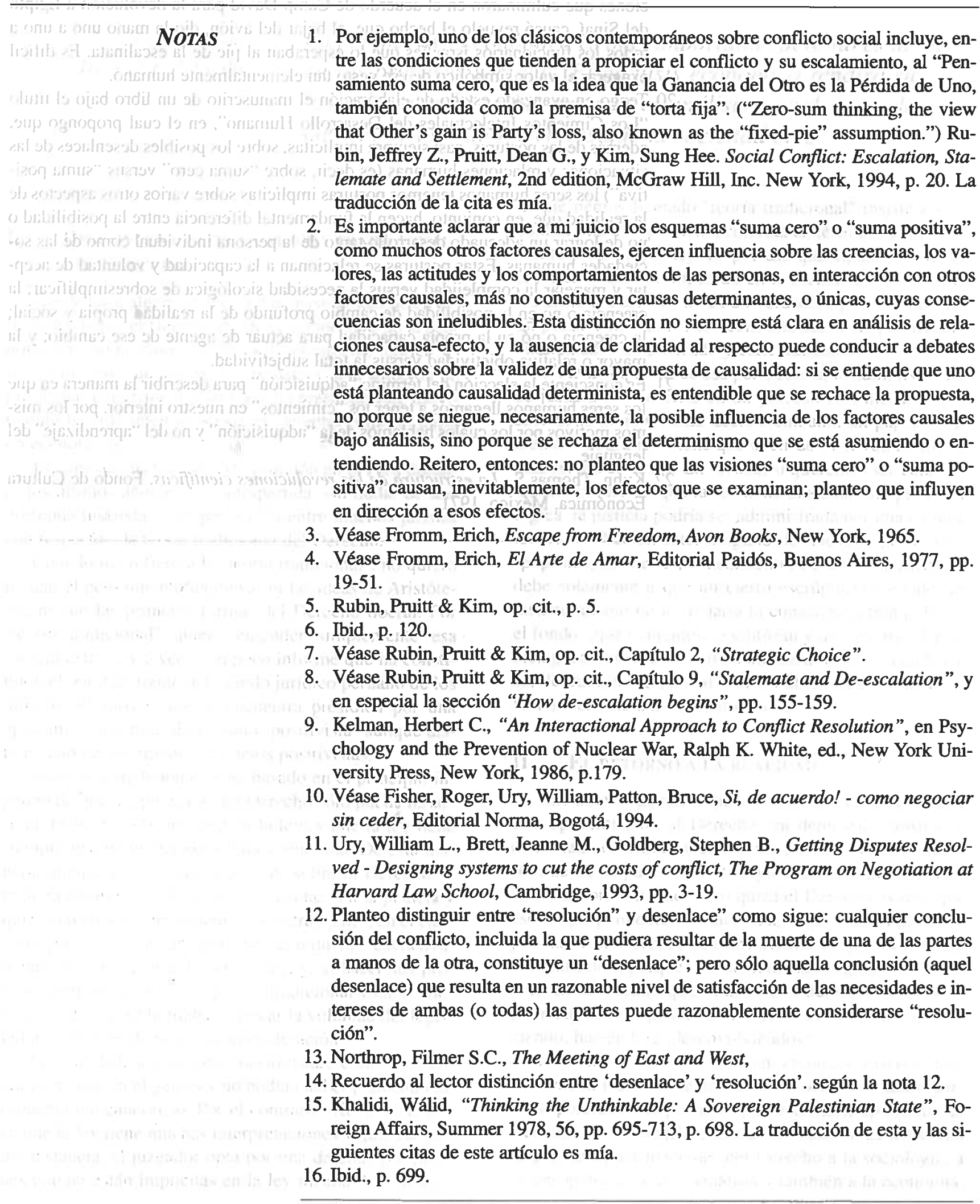




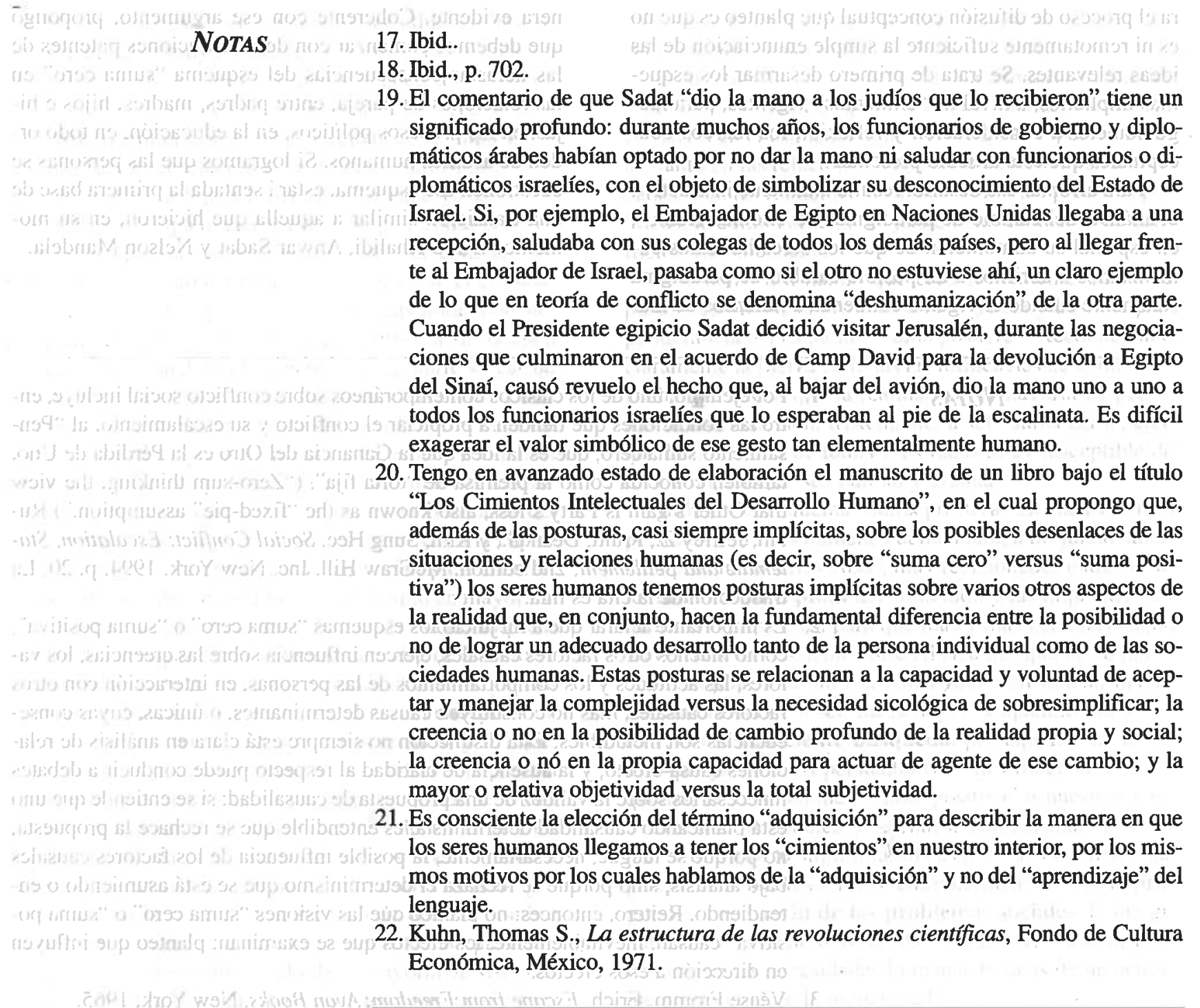

